\title{
Analysis of the preference and survival rates of ants in sugar and aspartame
}

\begin{abstract}
Today nutrition is an important factor in human health. The increased usage of artificial sweeteners create many problems in human health. Aspartame is used as a sweetener in low calorie diets because it has very low calories, but the issue of it is safety is controversial. The aim of this project is to study the effects of aspartame versus sugar on ants. It can help judge whether it is safe or not for humans use. First 20 fire ants are taken and placed in the T-maze and then $2 \mathrm{~g}$ of sugar is dissolved in distilled water. The study showed a considerable change in the two species of ants. In both the experiments using fire ants and weaver ants, more prefer sugar to aspartame. It can be concluded that the increased intake of aspartame causes a considerable effect in their survival rate of ants. So using ants, it helps to understand how aspartame effects ant's survival rate. By using this it helps to judge aspartame is not safe for human use. Actually the issue of safety of aspartame is very controversial, because it was initially developed as an ant poison and only changed to being considered non poisonous after it was realized that a lot more money could be made on it as "Sweetener".
\end{abstract}

Volume 3 Issue $6-2017$

\author{
Kavya S,' Kumar Sai Sailesh ${ }^{2}$ \\ 'Department of MHA, Little Flower Institute of Medical \\ Sciences and Research, India \\ 2Department of Physiology, DMWayanad Institute of Medical \\ Sciences, India
}

\section{Correspondence: Kumar Sai Sailesh, Department of} Physiology, DM Wayanad Institute of Medical Sciences, Naseera Nagar, Meppadi, Wayanad, Kerala, India, Email Saisailesh.kumar@gmail.com

Received: November 01, 2017| Published: November 20, 2017

Keywords: aspartame, sugar, ants, non poisonous, thorax, abdomen, calories

\section{Introduction}

Nutrition is important for human health. Aspartame is used as a sweetener in low calorie diets because it has very few calories, but the issue of its safety is controversial. Using ants to test the effects of aspartame versus sugar based on their preference and health effects can help judge whether it is safe of not for human consumption. ${ }^{1}$ Ants have 3 basic body parts-the head, abdomen and thorax. On their head, is their mouth, eyes and antennae. Using ants for this experiment because they have high sensory abilities than any other insects. Predators of ants includes lizards, birds, beetles, antlions and other insect eating mammals and humans. ${ }^{2}$ Ants defend themselves by biting, stinging and spraying unpleasant vinegar like scent. Using aspartame rather than sugar, the calorie intake can be reduced in many foods. Many food scientists and doctors still question its safety, especially when taken in large quantities and claim it can cause damage to the central nervous system and other vital organs. ${ }^{3,4}$ The present study aimed to analyze the preference and survival rates of ants in sugar and aspartame.

\section{Methodology}

\section{Materials required}

The materials required are fire ants-20, weaver ants-20, T-maze-I, Aspartame-2g, White sugar-2g, Watch glass-2, Distilled water $-600 \mathrm{ml}^{5,6}$

\section{Setting up of the experiment}

\section{Phase I}

A T-maze was taken and 20 fire ants were placed in it. Then $2 \mathrm{~g}$ of sugar is dissolved in $2 \mathrm{ml}$ of distilled water in watch glass and placed in the right half of the T-maze and is labeled as 'Sugar'. Then $2 \mathrm{~g}$ of aspartame is dissolved in $2 \mathrm{ml}$ of distilled water taken in a watch glass and placed on the left half of the T-maze and labeled as 'Aspartame'. The set up was left for 10 minutes and digital photographs of the feeding stations in two dishes were taken. The picture number, time and date was also recorded. The steps were repeated and each photo was examined at high magnification by counting the number of ants in each half of T-maze.

\section{Phase II}

The fire ants were replaced with the weaver ants in the T-maze. The same experiment was repeated. The setup was left for 10 minutes. The number of ants feeding on both the dishes was recorded. The experiment was repeated and the number of live ants in the T-maze was examined (Table 1). The number of dead ants were counted in the T-maze. Took the digital photograph of the feeding stations, in the two dishes (Figures 1-4)

Table I Total number of fire ants alive and dead in two feeding stations

\begin{tabular}{ll}
\hline Sugar & Aspartame \\
\hline 13 & 7
\end{tabular}

\section{TOTAL NUMBER OF ANTS ALIVE AND DEAD IN TWO FEEDING} STATIONS

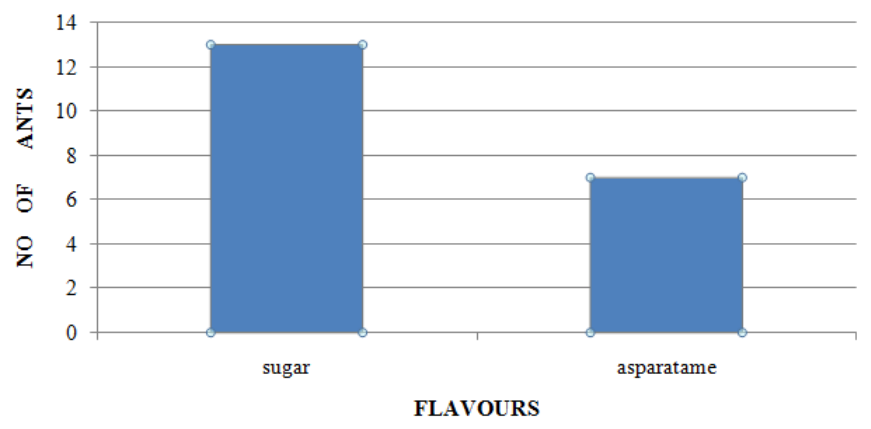

Figure I Graph shows the number of fire ants in two feeding stations. 


\section{$\%$ GRAPH OF FIRE ANTS ALIVE AND DEAD IN T-MAZE}

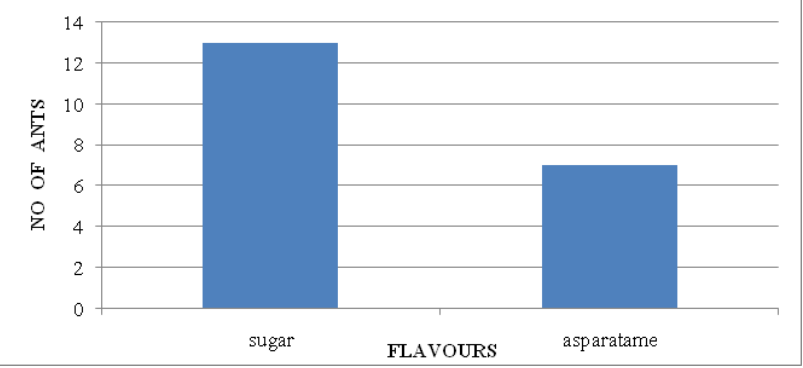

Figure $\mathbf{2} \%$ Graph of fire ants alive and dead in T-Maze.

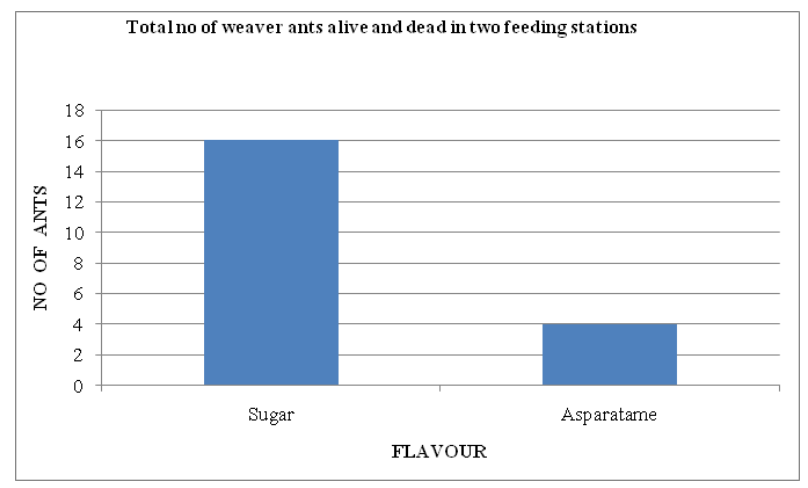

Figure 3 Graph shows the number of weaver ants in two feeding stations.

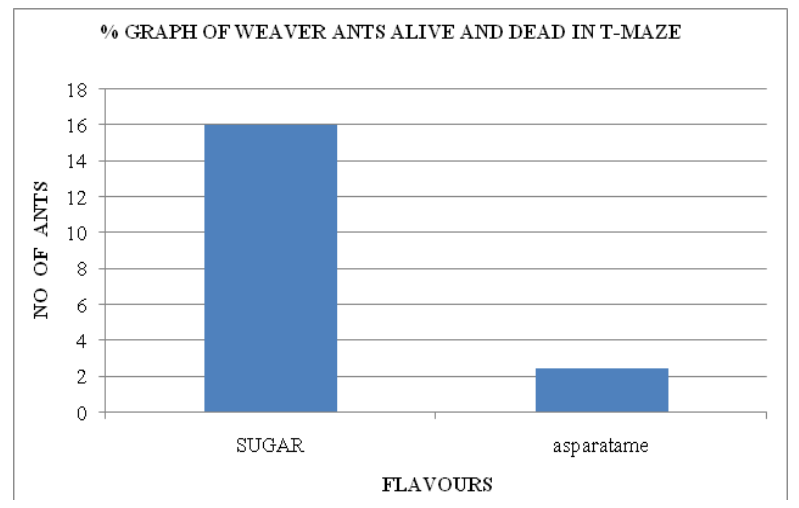

Figure $4 \%$ Graph of weaver Ants Alive and dead in T-Maze.

\section{Discussion}

The original purpose of this experiment was to determine if ants were attracted more to sugar or aspartame and to determine how it affected their survival rate. The results of the experiment were that ants prefer sugar to aspartame and also that more ants with access to aspartame died compared to those had access only sugar. In the first phase, 20 fire ants were taken I and the T-maze. It is observed that more ants are attracted to the sugar station. And it is observed that the number of ants which feeds aspartame causes death. In the second phase replaces the fire ants with weaver ants .In this phase also more ants are attracted to the sugar station and only few of them are feeds aspartame and some of them are died. In the both phases there are two types of ant species are used, one is fire ants (Solenopsis mandibularis) and other is weaver ants (Oecophylla smaragdina). In the both species, the number of survival rate is different. In the case of fire ants there 7 ants died, which fed on aspartame and in the case of weaver ants, 4 ants died which fed on aspartame. It is found that the number of survival rate in both species is different but in both phases, most of the ants died in the aspartame station. So it can be clearly stated that the effect of aspartame on the survival rate of ants. From this it can help to judge aspartame is not safe for human use. The increased usage of aspartame may create many health complications in humans.

\section{Conclusion}

Comparing to weaver ants it is seen that more ants died in aspartame than the fire ants. It can be concluded that the increased intake of aspartame causes a considerable effect in the survival rate of ants.

\section{Acknowledgements}

None.

\section{Conflict of interest}

The author declares no conflict of interest.

\section{References}

1. Sierra S. Companies that aware of the dangers of aspartame. USA; 2000 .

2. Elisa B. Ants nature children series Sherman turnpike. USA: Grolier Educational Corporation; 1999.

3. Tricid, Edgar, Raiford M. Facts About Aspartame. USA; 2014.

4. Shannon ME. Ant. World Book Encyclopedia; 1998. p. 520-521.

5. Cloe Wilson. Ant Microsoft Encarta 2000. 2001.

6. Worden BL. Harmful Effects of Aspartame. Echoing Eden. 1999;2(1):188. 